\title{
MECHANICAL PROPERTIES OF FIRST YEAR SEA ICE IN SAROMA LAGOON
}

by

\author{
Hisao Matsushita
}

Chiba Laboratory, Mitsui Engineering and Shipbuilding Co Ltd, 1, Yawata Kaigandori, Ichihara, Chiba 290, Japan

\section{NOBUYOSHI YASHIMA}

Ship and Ocean Project, MES 6-4, Tsukiji 5-chome, Chuo-ku, Tokyo 104, Japan

\begin{abstract}
This paper deals with compressive strength vs temperature characteristics $\left(-40^{\circ} \mathrm{C}\right.$ to $\left.-2^{\circ} \mathrm{C}\right)$, size effect (cross-sectional area of test specimen) and probability distribution of compressive strength and fracture toughness $\mathrm{K}_{\mathrm{IC}}$ (corresponding to notch effect in bending strength), of first year sea ice sampled from Saroma Lagoon. The main experimental results are as follows. (1) Temperature dependent compressive fracture modes: at temperatures of $-20^{\circ} \mathrm{C}$ to $0{ }^{\circ} \mathrm{C}$, crush fracture is dominant, and at temperatures of $-40^{\circ} \mathrm{C}$ to $-20^{\circ} \mathrm{C}$, brittle fracture is dominant. (2) The larger the cross-sectional area of a test specimen, the lower the compressive strength becomes. It is inferred that the number of weak spots increases with increase in the cross-sectional area of the test piece, which thus becomes more susceptible to fracture. (3) The scatter of compressive strength can be approximated by a normal distribution curve. (4) The $\mathrm{K}_{\mathrm{IC}}$ values of sea ice are below $10 \mathrm{~kg} / \mathrm{cm}^{2} \sqrt{\mathrm{cm}}$, though they change slightly depending on the dimensions of test pieces, the relative angle between crystal growth direction and load direction, environmental condition (air or water), and testing method.
\end{abstract}

\section{INTRODUCTION}

It is widely known that strength of ice varies in a complicated manner depending on several factors: ice structure, density, porosity, salinity, strain rate, size effect, notch effect, temperature effect etc. Strength characteristics of first year sea ice have been studied by Tabata (1964, 1966, 1977), Saeki (1978), and Nakajima (1979). However, there seem to be no studies of first year sea ice concerning (1) the relationship between compressive strength and temperature in a size range, (2) effects of cross-sectional area of a test specimen on compressive strength, (3) probability distribution of compressive strength, (4) size effect on fracture toughness $K_{I C}$, (5) dependence of the load direction on fracture toughness, and (6) dependence of environmental condition (air or water) and testing method on fracture toughness.

These characteristics are very important for estimating ice forces acting on off-shore structures in ice-covered seas, and are the subject of this paper.

\section{TEST PROCEDURES}

Sea ice is usually composed of layers, identified from the top down as snow ice, granular ice, and columnar ice (Weeks 1967). Test specimens were made from columnar ice of first year sea ice, sampled from Saroma Lagoon. Cylindrical specimens $7.5 \mathrm{~cm}$ in diameter and $7.5 \mathrm{~cm}$ long (size 1) were used for tests concerning temperature characteristics and probability distribution of compressive strength. Before tests at temperatures of $-40^{\circ} \mathrm{C}$ to $-10^{\circ} \mathrm{C}$, the specimens were chilled in a mixture of dry ice and alcohol. Larger specimens for testing size effects were cut in the shape of rectangular solids $15 \mathrm{~cm} \times 15 \mathrm{~cm} \mathrm{x} 40 \mathrm{~cm}$ (size 2) or $30 \mathrm{~cm} \times 30 \mathrm{~cm} \mathrm{x} 80 \mathrm{~cm}$ (size 3). Compressive strain rate was $10^{-3} / \mathrm{sec}$.

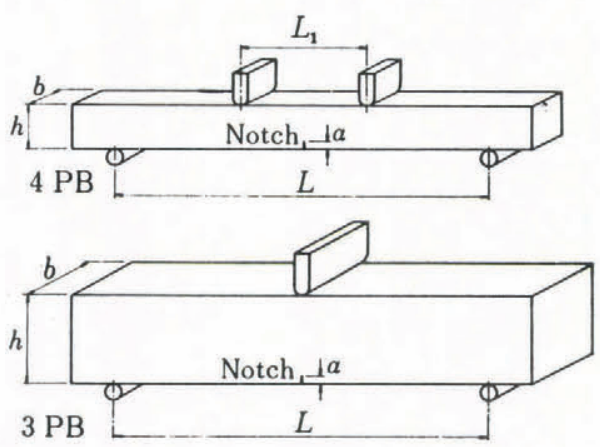

Fig.1. Notched specimens for bending test.

Three-point bend specimens (3PB) and four-point bend specimens (4PB) were used, as illustrated in Figure 1, to examine fracture toughness. Their dimensions are shown in Table 1. Their $\mathbf{K}$-value was calculated according to the formula specified in ASTM-E-399-78.

\section{TEST RESULTS AND DISCUSSION}

Compressive strength vs temperature

Figure 2 shows the relationship between temperature and compressive strength $\left(\sigma_{\mathrm{C}}\right)$ (refer to $(B)$ and $(C)$ ). Saeki's finding (Saeki and others 1978) on sea ice sampled from Saroma Lagoon (A) and the data reviewed by Haynes (1979) ((D) through Butkovich (1955), Wolfe and Thieme (1964)

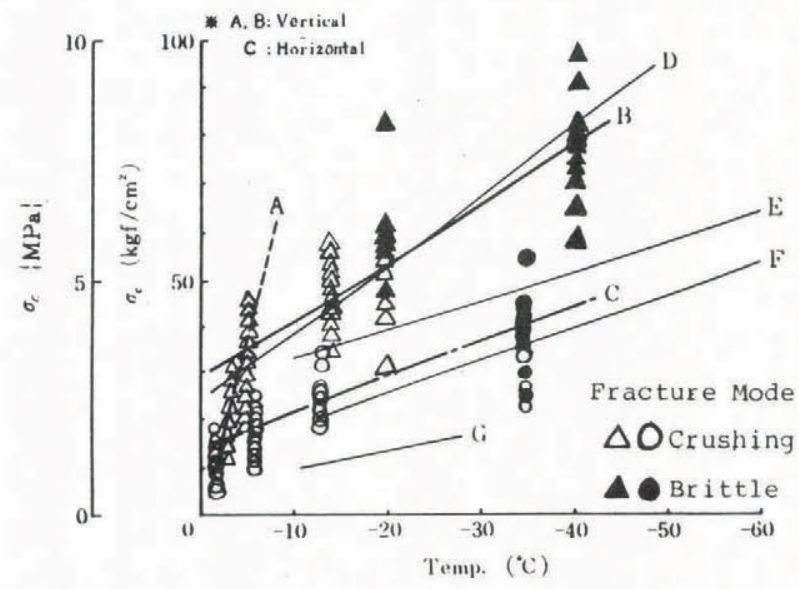

Fig.2. Dependance of temperature on compressive strengths of ice. sources: A; Saeki 1978: B and C; Matsushita 1981: D; Butkovich 1955: E and F; Wolfe and Thieme 1964: G; Dykins 1966. A, B and C refer to sea ice from Saroma Lagoon, D to clear lake ice, E and $G$ to laboratory ice, and $F$ to river ice. 
TABLE 1. RESULTS OF FRACTURE TOUGHNESS TEST FOR SEA ICE.

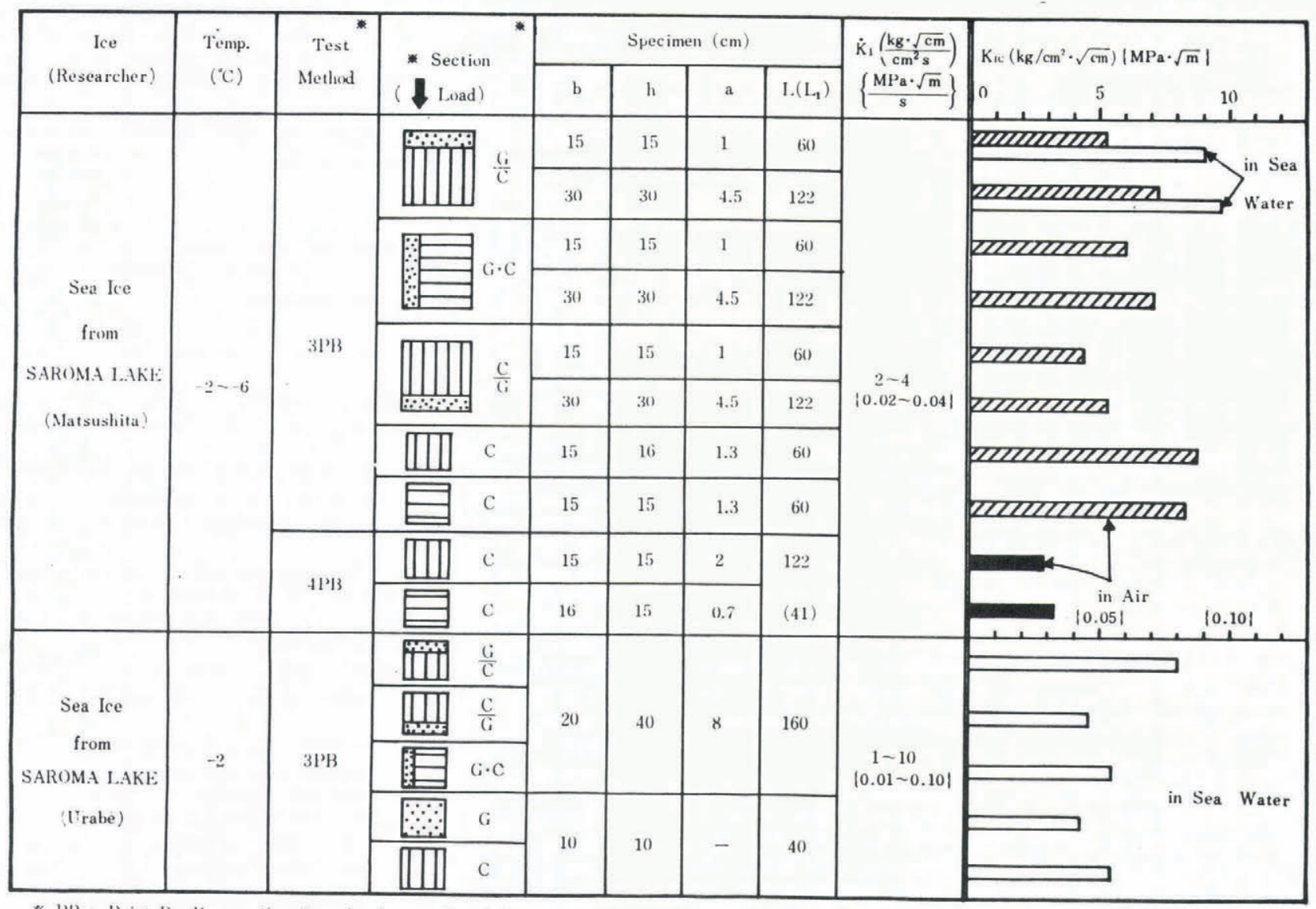

* P'B : Point Bending Ci: (iranular Ice $\mathrm{C}$ : Columnar Ice

and Dykins (1966) $(\mathrm{H})$ ) are also plotted in Figure 2. As demonstrated by Saeki's data (A), sea ice sampled from Saroma Lagoon shows a steep slope $\left(\sigma_{\mathrm{C}} /\right.$ temperature is about $\left.8 \mathrm{~kg} /\left(\mathrm{cm}^{2} \cdot{ }^{\circ} \mathrm{C}\right)\right)$ in the range of $-10^{\circ}$ to $0^{\circ} \mathrm{C}$, but the slope is reduced to about $1 \mathrm{~kg} /\left(\mathrm{cm}^{2} \cdot{ }^{\circ} \mathrm{C}\right)$ as demonstrated by our data, if the temperature is in the range of $-40^{\circ}$ to $0^{\circ} \mathrm{C}$. The temperature-dependent compressive fracture modes are classified as follows:

At temperatures of $-20^{\circ} \mathrm{C}$ to $0^{\circ} \mathrm{C}$, crush is dominant. The slope is steep.

At temperatures of $-40^{\circ} \mathrm{C}$ to $-20^{\circ} \mathrm{C}$, brittle fracture is dominant. The slope is less steep. Typical relationships between compressive stress and strain are shown in Figure 3. These modal changes may have affected the slope.

From Figure 2, it is found that the compressive strength of columnar ice varies depending on the relative
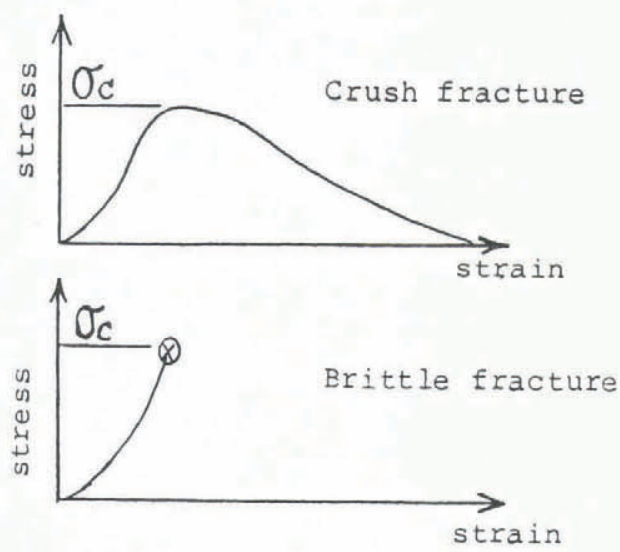

Fig.3. Typical relationships between compressive stress and strain. angle between the crystal growth direction and load direction. Compressive strength is about twice as great when the test specimen is loaded in the direction of crystal growth (B-Vertical: vertical test specimen) as when it is loaded normal to the crystal growth direction (C-Horizontal: horizontal test specimen). This phenomenon was explained by Tabata (1977) as follows. In a columnar crystal grain, the principal axis (C-direction) is normal to the longitudinal direction of the grain, that is, within a horizontal plane. The slip plane of the crystal thus lies within a perpendicular plane; when the ice sheet is compressed vertically, its slip plane is always parallel to the compressive force, and is least susceptible to it. On the other hand, the sample taken in the horizontal direction has crystal grains each of which shows various angles of slip planes against the compressive force, and is highly susceptible to slip.

\section{Probability distribution of compressive strength}

Figure 4 shows an example of frequency distribution of compressive strength in the temperature range of $-4^{\circ} \mathrm{C}$ to $-1{ }^{\circ} \mathrm{C}$, where crush mode is dominant. It was found that the scatter of compressive strength can be approximated by a normal distribution curve. The scatter of compressive strength is probably due to differences in the quantity and distribution of brine and pores in the sea ice, which cause hair cracks in the ice.

\section{Size effect on compressive strength}

Figure 5 shows the effect of size on compressive strength. In Figure 5, the ordinate represents non-dimensional compressive strength as relative values to the compressive strength $\left(\sigma_{\mathrm{co}}\right)$ of a size 1 test specimen of

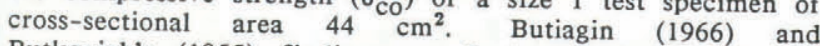
Butkovich's (1955) findings on freshwater ice, quoted in Tabata's report (1977), are also plotted in figure 5. A tendency can be seen that the larger the cross-sectional area of a test specimen, the lower the compressive strength 


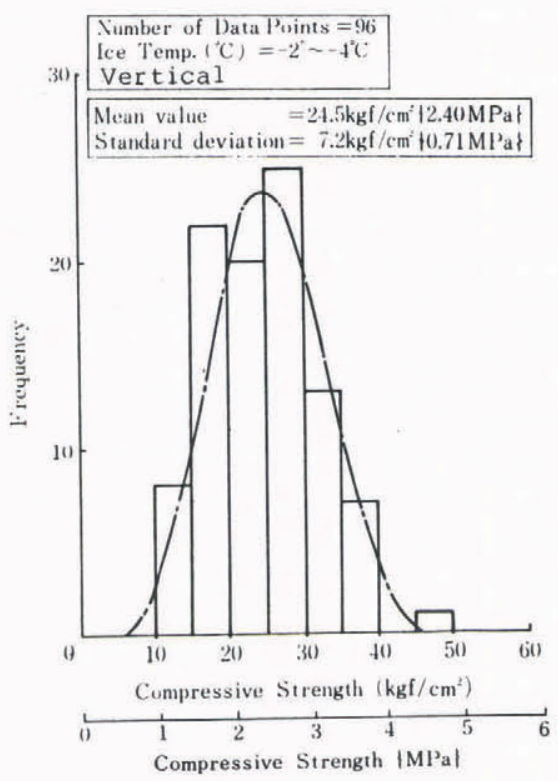

Fig.4. Distribution of compressive strength of sea ice.

becomes. It is inferred that the number of hair cracks increases with increase in the cross-sectional area of the specimen, which thus becomes more susceptible to fracture.

Fracture toughness $K_{\mathrm{IC}}$

The bending strength $\sigma_{\mathrm{b}}$ determined on three-point bending test specimens was in the range of about 4 to 8 $\mathrm{kg} / \mathrm{cm}^{2}$ with temperatures was from $-6^{\circ} \mathrm{C}$ to $-2^{\circ} \mathrm{C}$. The $\mathrm{K}_{\mathrm{IC}}$ values determined on notched bending test specimens are given in Table 1 . The $\mathrm{K}_{\mathrm{IC}}$ values of sea ice measured by Urabe and others (1979) are also listed. In general, these values are below $10 \mathrm{~kg} / \mathrm{cm}^{2} \sqrt{\mathrm{cm}}$, though they change slightly depending on the dimensions of the test specimens, the relative angle between crystal growth direction and load direction, environmental conditions (air or water), and testing method. Using $K=q \sqrt{\pi a}$, the critical crack length (2a) can be estimated as about 1 to $4 \mathrm{~cm}$. It is interesting to note that this is close to the length of brine channel along the horizontal cross section.

\section{CONCLUDING REMARKS}

In its natural form, sea ice exists close to its melting point. Unlike iron and other metals, the determination of mechanical properties of sea ice involves various delicate problems. Testing should therefore be carried out with all possible care and in a manner to obtain practical data

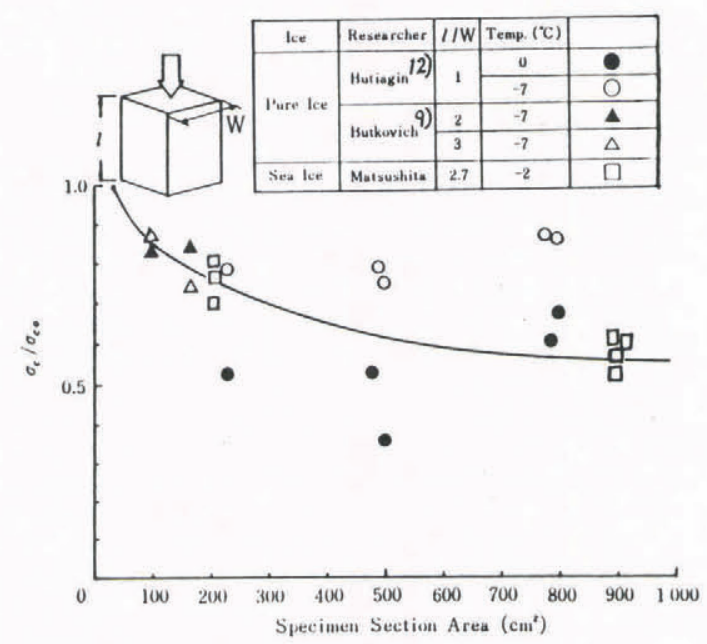

Fig.5. Dependence on specimen section area on compressive strength of sea ice. Sources: Butiagin 1966, Butkovich 1955, and Matsushita 1981. directly applicable to the design of offshore structures for ice-covered seas. To our regret, however, the current level of experimental and theoretical studies concerning sea ice physics is far short of this need. Although the introduction of fracture mechanics is an attractive attempt in this field, it should be noted that its careful handling will be needed because little is known about the strength characteristics of sea ice itself, particularly of the fracture mechanisms governing the strength of sea ice.

\section{REFERENCES}

ASTM-E399. 1978 Standard Test Method for Plane-strain Fracture Toughness of Metallic Materials. American Society for Testing and Materials

Butiagin I P 1966 [Strength of ice and ice cover.] Izdatelstvo "Nauka" Sibirtkoe Otdelenie, Novosibirisk (in Russian)

Butkovich T R 1955 Crushing strength of lake ice: interim report. Snow, Ice and Permafrost Research Establishment, Research Paper 15

Dykins J E 1966 Ice engineering tensile and bending properties of sea ice grown in a confined system. US Naval Civil Engineering Laboratory Technical Report, R415

Haynes F D 1979 Temperature effect on the uniaxial strength of ice. POAC 79: Proceedings of the 5th International Conference on Port and Ocean Engineering under Arctic Conditions: 667-681

Nakashima H and others 1979 Study of ice pressure on offshore structures. Nippon Kokan Technical Report 83 (in Japanese)

Saeki H and others 1978 Experimental study on the testing methods of strength and mechanical properties for sea ice. Symposium on Ice problems ... Luled ... 1978 International Association for Hydraulic Research: 135-149

Tabata T, Fujino K 1964 [Studies on mechanical properties of sea ice. VII. Measurement of flexural strength in situ.] Low Temperature Science, A, 22:147-154 (In Japanese with English summary)

Tabata $\mathrm{T}$ and others 1966 Studies of the mechanical properties of sea ice XI: the flexural strength of sea ice in situ. In: Oura $\mathrm{H}$ (ed) Physics of snow and ice. International Conference on Low Temperature Science ... 1966...Proceedings, 1(1): 539-530

Tabata T and others 1977 [Future prospects of coastal engineering.J Japan Science Foundation (in Japanese)

Weeks W, Assur A 1967 The mechanical properties of sea ice, 9. Cold Regions Science and Engineering, 2: Physical Science, C: Physics and Mechanics of Ice, II-C3.

Wolfe L H, Thieme J O 1964 Physical and thermal properties of frozen soil and ice. Journal of the Society of Petroleum Technology 